\title{
RESENHA \\ A Vida de Isaac Newton
}

\author{
por Richard S. Westfall (tradução de Vera Ribeiro), \\ Editora Nova Fronteira, 328 pp. (1995).
}

Recebido em 16/05/2001. Aceito em 06/08/2001

Inúmeros são os livros sobre a vida de Isaac Newton. Tanto em português quanto em outros idiomas encontramos textos que se propõem a descrever a vida deste que foi um dos maiores cientistas de todos os tempos. Entretanto, poucos são os livros que conseguem atingir tanto o público leigo quanto o especializado. Sem qualquer sombra de dúvida, o presente livro encontra-se entre esses poucos.

Como é sugerido pelo próprio título, o livro trata da biografia de Isaac Newton. Esta biografia retrata a vida pessoal e a carreira científica de Newton, fazendo uma descrição abrangente do homem, do cientista, do filósofo, do teólogo e da figura pública. Trata-se de uma versão condensada da obra de grande porte, $\mathrm{Ne}$ ver at Rest: A Biography of Isaac Newton, publicada pelo mesmo autor em 1980 .

Conforme o autor deixa claro no prefácio, seu objetivo ao escrever este livro é o de produzir uma biografia completa da vida de Newton, tanto da sua carreira científica como da sua vida pessoal, de uma maneira acessível ao público em geral. Sendo este o objetivo, sem dúvidas ele foi alcançado.

O livro é dividido em treze capítulos que procuram analisar os 84 anos de vida de Newton.

O capítulo 1, intitulado "Um garoto sóbrio, silencioso e pensativo", descreve a infância e adolescência de Newton, desde o seu nascimento no Natal de 1642 até sua transferência para o Trinity College em Cambridge, em junho de 1661. Neste capítulo o autor apresenta indícios de que Newton já quando criança demonstravase uma pessoa diferente, não só por suas habilidades para a invenção de aparelhos mecânicos como também por seu isolamento e aversão a outras crianças.

O capítulo 2, "O estudante solitário", retrata os quatro primeiros anos de Newton no Trinity College (1661-1664) em Cambridge. "Newton entrou no Trinity como um subsizar - o estudante pobre que ganhava seu sustento prestando serviços domésticos aos professores, aos alunos não subvencionados (estudantes ricos...) e aos pensionistas (alunos meramente abastados)." Newton não foi um aluno brilhante nos conteúdos da escola, pois não se interessava muito por eles, em geral estudava rapidamente tais conteúdos nas vésperas dos exames, ocupando a maior parte do seu tempo com outros assuntos mais complexos como a geometria de Descartes. Entretanto, alguns indícios apontam que já nessa época Newton escreveu seu primeiro trabalho, não publicado, intitulado "Algumas questões filosóficas".

Em "Anni mirabiles", capítulo 3, o autor faz uma descrição do período mais fértil da vida intelectual de Newton (anos de 1664 a 1666). Neste período Newton teve que voltar para a fazenda de seus pais, pois a peste bubônica que assolou a Inglaterra forçou o fechamento das universidades. Em Woolsthorpe, sua terra natal, Newton desenvolveu as bases de toda a sua obra, como ele próprio relatou: "No início do ano de 1665, descobri o método de aproximação a uma série desse tipo \& a regra para reduzir qualquer potência de qualquer binômio a tal série. No mesmo ano, em maio, descobri o método das tangentes de Gregory \& Slusius \&, em novembro obtive o método direto das fluxões, \& no ano seguinte, em janeiro, a teoria das cores, \& em maio seguinte desvendei o método inverso das fluxões. \& no mesmo ano, comecei a pensar na gravidade como se estendendo até a órbita da Lua \& ... deduzi que as forças que mantêm os planetas em suas órbitas devem [variar], reciprocamente, com o quadrado de sua distância do centro em torno do qual eles giram... . Tudo isso foi nos dois anos da peste, 1665 - 1666. Pois, nessa época, eu estava no auge de minha fase de invenção \& me interessava mais pela matemática \& pela filosofia do que em qualquer ocasião posterior." O autor faz uma análise pormenorizada deste período da vida de Newton, destacando que neste três anos Newton lançara as bases sobre as quais construiria sua obra, porém, nada estava concluído no final de 1666.

O capítulo 4, intitulado "Professor lucasiano", retrata a trajetória que conduziu Newton à posição de professor lucasiano de Matemática do Trinity. Contase que Newton foi um professor medíocre, que não conseguia transmitir suas idéias com clareza e que freqüentemente faltava às aulas. Nesta mesma época 
começam as correspondências entre Newton e Oldenburg, secretário da Royal Society. A partir desta época Newton sai de seu anonimato para nunca mais voltar.

O capítulo 5, "Publicação e crise", ocupa-se em analisar as conseqüências da primeira publicação de Newton, o artigo sobre as cores, remetido à Royal Society no início de 1672. Este artigo foi alvo de muitas críticas rebatidas com irritação por Newton. A partir desta data, Newton trava uma batalha intelectual com três personagens que vão protagonizar outros episódios de sua vida: Robert Hooke, Christiaan Huygens e Leibniz. Correspondências calorosas são trocadas entre eles, o que vai contribuir para Newton tornar-se averso a qualquer tipo de publicação de seus trabalhos. Neste capítulo podemos perceber muitos traços da personalidade de Newton, herdados talvez de sua infância.

Em "Rebeldia", capítulo 6, Newton, como forma de protesto às críticas recebidas por seus trabalhos, resolve abandonar seus estudos em filosofia e matemática dedicando-se à alquimia e teologia. Nesta época, Newton, que normalmente era um sujeito sovina, resolve gastar parte de suas economias na aquisição de livros sobre alquimia e também em equipamentos para a montagem de um pequeno laboratório em seu escritório. Newton escreveu alguns tratados de alquimia que não tiveram muita importância, até por que não foram publicados. Já em teologia, os tratados de Newton, caso tivessem sido publicados, provavelmente dariam o que falar e talvez até o condenassem à fogueira, isso por que Newton não era muito ortodoxo, seus artigos criticavam a santíssima trindade ou o trinitarismo em contraposição ao unitarismo.

Em 1679, morre a mãe de Newton e a partir desta época Newton vai viver seus "Anos de silêncio" (capítulo 7) em que vai mergulhar ainda mais em seus estudos teológicos e alquímicos. Neste capítulo, o autor faz uma descrição mais detalhada dos trabalhos de Newton nessas duas áreas, que serão deixadas de lado por volta de 1684 com a visita de Edmond Halley.

O capítulo 8, intitulado "Principia", como o próprio nome sugere trata da gênese da grande obra de Newton: Os Princípios Matemáticos da Filosofia Natural. O autor faz uma descrição detalhadíssima dos fatores que antecederam a publicação dos Principia e dos fatores que permearam o processo. Segundo palavras do autor: "Os Principia não foram apenas a realização monumental de Newton. Foram também a guinada decisiva em sua vida. Como sabemos por seus papéis, ele havia realizado prodígios em vários campos. $\mathrm{E}$, como também sabemos, não concluíra nada. ... Se Newton houvesse morrido em 1684 e seus papéis se preservassem, saberíamos por eles que um gênio tinha vivido. Mas, em vez de enaltecê-lo como uma figura que moldou a intelectualidade moderna, no máximo o mencionaríamos em pequenos parágrafos, lamentando a impossibilidade de atingir a plena realização." O capítulo traz também uma descrição da estruturação dos Prin- cipia, os assuntos que são tratados em cada volume, como se divide cada volume e assim por diante.

A "Revolução", capítulo 9, apresenta as conseqüências da publicação dos Principia, não só na vida de Newton mas, em toda a sociedade da época. O capítulo conta um pouco sobre a divulgação da obra em toda a Europa e suas repercussões nos círculos intelectuais. O capítulo ainda trata do episódio, posterior à publicação dos Principia, do colapso nervoso de Newton que, segundo alguns relatos, teria durado cerca de um ano e meio.

O capítulo 10, intitulado "A Casa da Moeda", descreve o contexto que envolveu a nomeação de Newton para trabalhar na Casa da Moeda em Londres, em 1696, e os fatores que promoveram sua ascensão para o cargo de diretor em 1699. O autor apresenta detalhes do trabalho desenvolvido por Newton, merecendo destaque a caça aos falsificadores de moedas, atividade que Newton desempenhou como ninguém. O capítulo traz ainda relatos sobre a atividade de Newton no Parlamento Britânico, atividade que ele abandonou em 1705.

O capítulo 11, "Presidente da Royal Society", analisa a longa trajetória de Newton enquanto presidente da Royal Society, desde sua nomeação, em 1703 com a morte de Hooke, até sua morte, em 1727. Neste capítulo podemos perceber traços de mudanças na personalidade de Newton, segundo palavras do autor: "Em Newton, a impaciência diante da contradição, que em sua juventude se manifestara como uma disposição de jogar fora a cautela, contestando autoridades estabelecidas como Hooke, transformou-se na velhice, num desejo tirânico de dominação, um traço antipático que é impossível ignorar." Neste capítulo encontramos, também, detalhes sobre a publicação da segunda obra de Newton, a $O p$ ticks, datada de 16 de fevereiro de 1704 .

No capítulo 12, intitulado "A disputa pela prioridade", o autor procura fornecer uma leitura imparcial do episódio que envolveu Leibniz e Newton na disputa pela prioridade de invenção do cálculo. Segundo as palavras do autor, a disputa pela prioridade demonstrou a "incapacidade de ambos de compartilhá-la amistosamente". Esta disputa atingiu proporções tais que, mesmo com a morte de Leibniz em 1716, levaram-se mais seis anos para que ela se dissipasse.

Finalmente, o capítulo 13 trata dos "Anos de declínio". O autor procura fazer uma análise da etapa final da vida de Newton, desde o fim da disputa pela prioridade, em 1723, até a sua morte em 1727. Como o título do capítulo sugere, esses foram anos de declínio, como era de se esperar num homem de sua idade.

O livro traz uma riqueza incrível de detalhes das diversas etapas da vida de Newton. Em alguns momentos o autor expõe fatos com tanta clareza e realismo que nos sentimos vivenciando tais fatos. A contextualização dos episódios também é outra característica marcante na obra. Além disso, visando atingir o público em geral, o autor poupa o uso de linguagem matemática e, mesmo 
quando esta é inevitável, é apresentada de forma a não prejudicar o entendimento dos fatos.

Em vários momentos do decurso da história o autor apresenta suas interpretações pessoais. Sempre que faz isso ele se justifica e apresenta argumentações muito plausíveis para defender seu ponto de vista. Sua argumentação sempre se baseia nos indícios históricos e ou na contextualização dos fatos. Em outros momentos em que pretende fazer uma leitura imparcial dos acontecimentos, como no caso da disputa pela prioridade, ele a faz de uma maneira admirável, conseguindo manter-se completamente neutro e externo às questões.

$\mathrm{O}$ autor mostra-se muito bem informado sobre o assunto que pretende analisar. Todos os fatos, por mais detalhados que sejam, apresentam um respaldo histórico bastante confiável, quer seja por meio de relatos de terceiros quer sejam por correspondências do próprio Newton transcritos ao longo do texto. Quando algum fato não possui uma documentação que garanta sua autenticidade o autor procura deixar isto bem claro para o leitor, o mesmo acontece quando as interpretações são baseadas em informações de outros biógrafos de Newton, nestes casos ele preocupa-se inclusive em citar as fontes. Além de tudo isso, no final do livro ele apresenta um ensaio bibliográfico de quatro páginas em que, não só cita bibliografias para consulta e aprofundamento como também comenta cada bibliografia citada.

Trata-se realmente de uma belíssima obra, a começar pela capa: o primeiro retrato pintado de Newton, aos 46 anos, dividindo espaço com algumas representações matemáticas, alguns instrumentos astronômico e mecânicos e uma grande nuvem preta envolvida por um brilho que pode ser entendido como uma metáfora à luz que Newton lançou às trevas em que se escondia a Ciência. A linguagem utilizada pelo autor também merece destaque. Uma linguagem clara porém polida, riquíssima em palavras envolventes e penetrantes como num bom romance. A leitura do livro tornase muito agradável e estimulante. O texto também é rico em ilustrações, não em gravuras, que são poucas porém oportunas, mas, em correspondências originais entre Newton e os diversos personagens que fizeram parte de sua história, e em cópias de memorandos oficiais que ajudam a contar a história deste grande homem que foi Newton. Todas estas ilustrações fazem com que o leitor mergulhe na época em que Newton viveu e vibre com seus feitos ou se assuste com seu estranho comportamento.

Richard Westfall é um dos maiores biógrafos de Newton. Ele é professor emérito do Departamento de História e Filosofia da Ciência da Universidade de Indiana. Sua grande obra sobre Newton, Never at Rest, ganhou o prêmio Leo Gershoy da Associação Americana de História.

A presente versão condensada da sua grande obra é literatura obrigatória para professores de Física e é uma ótima indicação de leitura, não só para aqueles que se interessam pela vida de Newton mas também para aqueles que simplesmente procuram uma literatura de qualidade.

Renato Pontone Junior

Mestrando em Educação em Ciências, FaE - UFMG

Coordenador do Departamento de Física do Colégio Batista Mineiro

Belo Horizonte, MG

E-mail: pontone@zipmail.com.br 